\title{
Successful management of total placenta previa with placenta accreta presenting with massive obstetric hemorrhage: a case report
}

\author{
Sairem Mangolnganbi Chanu', Biswajit Dey ${ }^{2 *}$, Samarjit Dey ${ }^{3}$, \\ Khairul Hadi $^{3}$, Nalini Sharma ${ }^{1}$, Vandana Raphael ${ }^{2}$
}

${ }^{1}$ Department of Obstetrics and Gynecology, ${ }^{2}$ Department of Pathology, ${ }^{3}$ Department of Anesthesiology, NEIGRIHMS, Shillong, Meghalaya, India

Received: 06 June 2018

Accepted: 29 June 2018

*Correspondence:

Dr. Biswajit Dey,

E-mail: drbish25@rediffmail.com

Copyright: () the author(s), publisher and licensee Medip Academy. This is an open-access article distributed under the terms of the Creative Commons Attribution Non-Commercial License, which permits unrestricted non-commercial use, distribution, and reproduction in any medium, provided the original work is properly cited.

\begin{abstract}
Placenta previa and placenta accreta are important causes of serious fetal and maternal morbidity and even mortality necessitating hysterectomy. We report a case of total placenta previa with accreta in a 39 -year-old female in the $32+2$ weeks of pregnancy with successful delivery by cesarean. However, hysterectomy was performed to control postpartum hemorrhage.
\end{abstract}

Keywords: Hemorrhage, Hysterectomy, Placenta

\section{INTRODUCTION}

Placental disorders are disorders which occur during attachment of the placenta to the uterine wall. ${ }^{1}$ Placental disorders such as placenta previa and placenta accreta are associated with vaginal bleeding. ${ }^{2}$ The prevalence of these disorders is estimated to be around $0.3 \%{ }^{1}$ Placenta accreta is present when there is excessive invasion during placentation extending beyond the decidua basalis. When the placental invasion is deep into the myometrium, this is known as placenta increta.

When the placental penetration is along the entire thickness of uterine wall and reaches the serosa, this is known as placenta percreta. ${ }^{1}$ Placental disorders also include low-lying placenta (placental edge closest to the cervix $<2 \mathrm{~cm}$ from the inner os), marginal placenta previa (placenta extends to the edge of the cervix), partial placenta previa (a portion of the cervix is covered by the placenta), and total placenta previa (inner os completely covered by the placenta). ${ }^{1}$ Both these placental disorders, i.e. placenta previa and placenta accreta are associated with increased maternal and fetal morbidity and mortality. ${ }^{3}$ Authors report a case of total placenta previa with placenta accreta in a 39-year-old female in the 32 nd week of pregnancy.

\section{CASE REPORT}

A 39-year-old female with gravida 2 and para 1 presented with lower abdominal pain at $32+2$ weeks of pregnancy. She had a history of prior lower segment cesarean section three years earlier. A diagnosis of total placenta previa was made following examination on admission. She was advised complete bed rest and oral magnesium sulphate. Abdominal ultrasonography (USG) showed an intact singleton pregnancy appropriately developed for age. Cervical length on vaginal sonography was $35 \mathrm{~mm}$ without funnelling.

The placenta covered the inner os. Ultrasonography (USG) raised the suspicion of placenta accreta. Magnetic resonance imaging (MRI) was advised however, she complained of massive bleeding per vaginum and was rushed to the emergency. Her blood pressure was 70/50 
$\mathrm{mm}$ of $\mathrm{Hg}$ and pulse rate of $126 /$ minute. The fetal heart rate was 226/ minute. Her haemoglobin was 6.4 gm\%. The patient was resuscitated with Ringer's Lactate solution. An emergency cesarean section was planned. Intraoperatively engorged veins were seen over the lower uterine segment and bladder. The entire lower anterior uterine wall consisted only of a thin translucent layer of peritoneum with the placenta clearly visible through it. These clinical findings led to a diagnosis of placenta accreta. The uterine incision was made in the lower part of the upper segment. A healthy female baby weighing $1.7 \mathrm{~kg}$ was delivered. Intravenous methylergonovine maleate was administered and the uterus started contracting. However profuse bleeding started from the partially separated placenta and her blood pressure dropped down to $60 / 40 \mathrm{~mm}$ of $\mathrm{Hg}$. Placental bed was compressed with multiple wet mops. Hysterectomy without adnexectomy was performed. The intraoperative blood loss was estimated to be 3.5 litres, which was simultaneously managed by transfusing 8 units of packed red cells concentrations, 8 units of fresh frozen plasma and 4 units of platelets intraoperatively. The uterus with partially attached placenta was sent for histological examination (Figure 1).

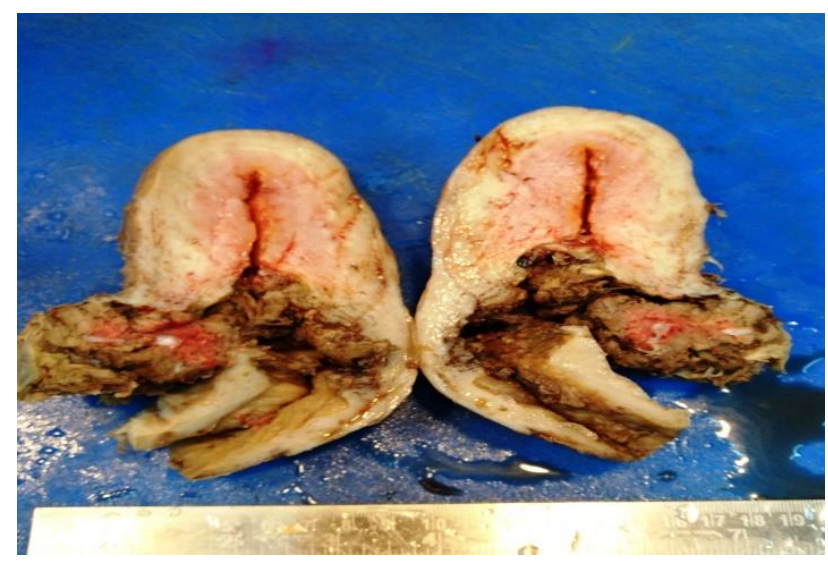

Figure 1: The uterus with partially attached placenta.

Histopathological examination confirmed the diagnosis of total placenta previa with placenta accreta (Figure 2).

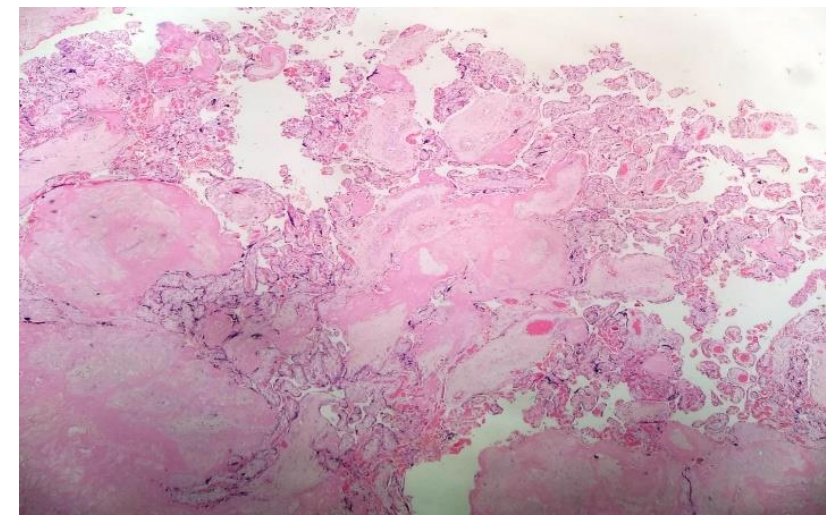

Figure 2: Histopathology showing placenta accreta (H and $\mathrm{E}, 100 \mathrm{x})$.
She developed deep vein thrombosis on $4^{\text {th }}$ post-operative day, which was managed by anticoagulants. She was discharged on $17^{\text {th }}$ postoperative day.

\section{DISCUSSION}

Normal placental structure and function is an essential prerequisite for a healthy pregnancy. ${ }^{4}$ Abnormalities of the placenta and umbilical cord significantly increase the risk of fetal and maternal morbidity and morbidity. ${ }^{5,6}$ Very rarely these abnormalities have favourable fetal outcome however such cases require active interventions. $^{5}$

Placenta previa and placenta accreta are important causes of serious fetal and maternal morbidity and even mortality. ${ }^{3}$ Around $30 \%$ of cases of placenta previa are associated with placenta accreta. $^{3}$ A previous prior uterine surgery like cesarean section is the most common risk factor. ${ }^{1}$ Other risk factors include endometrial scarring due to endometritis and endometrial curettage, maternal age more than 35 years, multiparity, submucous fibroids, and deposition of the embryo close to the cervix during embryo transfer with assisted reproductive technology. ${ }^{7}$ In the present case, risk factors such as previous cesarean section and increased maternal age were present.

First line imaging modalities include gray-scale ultrasound and color Doppler for the diagnosis of placental disorders. ${ }^{1,8}$ MRI is used as an adjunct tool to improve sensitivity when sonographic examination is equivocal or when the placenta cannot be reliably visualized. ${ }^{1,8}$ Overall, gray scale USG is sufficient to diagnose placenta accreta, with a sensitivity of $77-87 \%$ and specificity of 96-98\%. ${ }^{9}$ Antepartum diagnosis of this condition helps the obstetrician to demarcate areas of placenta that are adherent to uterine myometrium. Knowing this the obstetrician can plan the management accordingly and can demarcate the areas of placenta that require resection. In the present case, placenta previa was evident on gray-scale USG. Placenta accreta was suspected on USG and MRI was advised to confirm it. However, MRI could not be done as the patient complained of massive bleeding per vaginum and was taken up for emergency resuscitation followed by surgical management.

If placental disorders are only recognized in labor, the lack of uterine tone can result in life-threatening hemorrhage. ${ }^{1}$ Cesarean hysterectomy is the standard management in cases of intrapartum and postpartum hemorrhage for placenta previa accreta. ${ }^{10}$ Nowadays, conservative interventions are recommended before radical procedure in order to preserve fertility. ${ }^{10}$ The conservative options for postpartum hemorrhage include uterotonics drugs, external compression with uterine sutures (B-Lynch, Hayman, Cho), intrauterine packing (Bakri balloon), and selective devascularization by ligation or embolization of the uterine artery. ${ }^{10}$ In the 
present case, as intrapartum hemorrhage could not be controlled by uterotonics drugs and compression, cesarean hysterectomy was performed.

Funding: No funding sources

Conflict of interest: None declared

Ethical approval: Not Required

\section{REFERENCES}

1. Findeklee F, Costa SD. Placenta accreta and total placenta previa in the 19th week of pregnancy. Geburtshilfe Frauenheilkd. 2015;75:839-43.

2. Silver RM. Abnormal placentation: Placenta previa, vasa previa, and placenta accreta. Obstet Gynecol. 2015; 126:654-68.

3. Finberg HJ, Williams JW. Prospective sonographic diagnosis in patient with placenta previa and prior cesarean section. J Ultrasound Med. 1992;11:333-43.

4. Heazell A. Abnormalities of the placenta. BMC Pregnancy Childbirth. 2012;12(Suppl 1):A2.

5. Rudrapal GS, Chanu SM, Dey B, Nandwani M, Singh AS. Successful pregnancy outcome in a case of large placental chorangioma in an elderly primigravida. Ann Int Med Den Res 2017;3(S1):1-2.
6. Panda S, Jha V, Khonglah Y, Dey B. A multivessel umbilical cord with a single umbilical artery. J Clin Diagn Res 2013;7:1453-4.

7. Miller DA, Chollet JA, Goodwin TM. Clinical risk factors for placenta previa-placenta accreta. Am J Obstet Gynecol. 1997; 177:210-4.

8. Maher M, Abdelaziz A, Bazeed M. Diagnostic accuracy of ultrasound and MRI in the prenatal diagnosis of placenta accreta. Acta Obstet Gynecol Scand. 2013;92:1017-22.

9. Committee on Obstetric Practice. Committee Opinion No. 529: placenta accreta. Obstet Gynecology. 2012;120:207-11.

10. Canonico S, Arduini M, Epicoco G, Luzi G, Arena $S$, Clerici $G$ et al. Placenta previa percreta: a case report of successful management via conservative surgery. Case Rep Obstet Gynecol. 2013; 2013:702067.

Cite this article as: Chanu SM, Dey B, Dey S, Hadi K. Sharma N, Raphael V. Successful management of total placenta previa with placenta accreta presenting with massive obstetric hemorrhage: a case report. Int J Reprod Contracept Obstet Gynecol 2018;7:3417-9. 